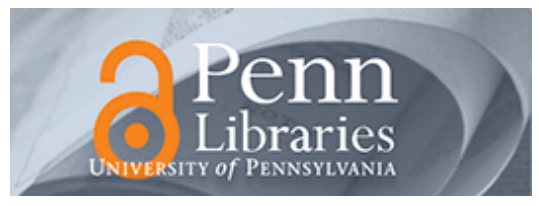

University of Pennsylvania ScholarlyCommons

$1-1-2005$

\title{
Second Language Acquisition Research and Applied Linguistics
}

Teresa Pica

University of Pennsylvania, teresap@gse.upenn.edu

Follow this and additional works at: https://repository.upenn.edu/gse_pubs

Part of the Bilingual, Multilingual, and Multicultural Education Commons

\section{Recommended Citation}

Pica, T. (2005). Second Language Acquisition Research and Applied Linguistics. Retrieved from https://repository.upenn.edu/gse_pubs/34

Postprint version. Published in Handbook of Research in Second Language Teaching and Learning, edited by Eli Hinkel (Mahway, N.J.: L. Erlbaum Associates, Inc., 2005), pages 263-280.

This paper is posted at ScholarlyCommons. https://repository.upenn.edu/gse_pubs/34

For more information, please contact repository@pobox.upenn.edu. 


\title{
Second Language Acquisition Research and Applied Linguistics
}

\author{
Abstract \\ The purpose of this paper is to provide an overview of second language acquisition (SLA) research over \\ the past several decades, and to highlight the ways in which it has retained its original applied and \\ linguistic interests, and enhanced them by addressing questions about acquisition processes. As the \\ paper will illustrate, SLA research has become increasingly bi-directional and multi-faceted in its \\ applications. These many applications to and from the study of SLA reflect the robustness and vitality of \\ the field. \\ Disciplines \\ Bilingual, Multilingual, and Multicultural Education

\section{Comments} \\ Postprint version. Published in Handbook of Research in Second Language Teaching and Learning, edited \\ by Eli Hinkel (Mahway, N.J.: L. Erlbaum Associates, Inc., 2005), pages 263-280.
}




\title{
Second Language Acquisition Research and Applied Linguistics Teresa Pica
}

\begin{abstract}
The purpose of this paper is to provide an overview of second language acquisition (SLA) research over the past several decades, and to highlight the ways in which it has retained its original applied and linguistic interests, and enhanced them by addressing questions about acquisition processes. As the paper will illustrate, SLA research has become increasingly bi-directional and multifaceted in its applications. These many applications to and from the study of SLA reflect the robustness and vitality of the field.
\end{abstract}

\section{INTRODUCTION}

Research on second language acquisition (SLA) has expanded enormously since its inception. Studies of SLA have increased in quantity as researchers have addressed a wider range of topics, asked new questions and worked within multiple methodologies. At the same time, the field has become increasingly bidirectional and multi-faceted in its applications. As new theories and research have emerged on language, and even more so, on learning, their application to the study of SLA has been fruitful. It has led to long needed explanations about developmental regularities and persistent difficulties, and has opened up new lines of research on the processes and sequences of second language (L2) development.

The application of newer findings from the study of SLA to educational concerns has both informed and sustained long standing debates about the role of the learner's consciousness in the SLA process, and about the nature of the learner's input needs and requirements. A modest, but increasing number of SLA research findings has had direct application to instructional decisions. Most other findings have served as a resource to inform teaching practice. The many applications to and from the study of SLA. are therefore the focus of this paper. 


\section{DISCIPLINARY CONTEXTS}

\section{SLA research and applied linguistics}

The study SLA is a rich and varied enterprise, carried out by researchers, whose interests and training often lie in broader disciplines of linguistics, psychology, sociology, and education. Yet the field is most commonly associated with the domain of applied linguistics, reflecting a time when this latter field focused on practical problems and concerns in language teaching, and attempted to resolve them through the application of linguistic theories. Both fields have expanded over the years. Their internal growth has enriched and elaborated their relationship.

Defining and describing research on SLA within the field of applied linguistics was once a straightforward task. Questions focused on practical concerns in language teaching, and were addressed through linguistic principles and psychological theories of learning. At the time of its inception, the field of applied linguistics was guided by theories from linguistic structuralism and behaviorist psychology. Language was characterized as a system that could be classified into sounds and structures. Language acquisition was seen as habit formation, best served as students imitated and practiced these sounds and structures, and were given positive reinforcement or corrective feedback as needed.

Very much an applied enterprise, this research followed an approach that came to be called "contrastive analysis" (Lado 1957). Typically, a comparison would be made between the L2 to be learned and the L1 of the learner. Drill, practice, and correction would follow on those areas of the L2 that differed from those of the L1 so that L1 "interference" could be avoided, and L2 habits could be formed. Unfortunately, this approach seldom worked, as learners did not appear to be developmentally ready to imitate many L2 structures they were given, and as linguists found it impossible to perform contrastive analyses on a feature by feature basis. Even after many years of practice, learners would wind up with 
little understanding of the L2 and limited ability to use it as a means of communication.

Both fields have broadened considerably over the years, as new views of language, the learner and the learning process have inspired further research. Many of the issues that arose regarding L1 interference, drill, practice, and correction can now be viewed in light of later work in the field. Recent research findings have pointed to L1 contributions as downplayed L1 interference. They have redefined practice as learner-centered, knowledge-based activity, and revitalized the role of corrective feedback, by identifying contexts in which it can be effective, possibly even vital, to success. (See respectively, research by Eckman 1977; studies by DeKeyser 1997; deGraff 1997; and theoretical articles by Doughty 2002; Long 1996; Schmidt 1995 and later parts of this paper). This work has enriched the field of applied linguistics, and shed further light on the process of SLA.

\section{SLA research and language acquisition studies}

SLA research can also be placed within the domain of language acquisition studies, together with studies on bilingualism, as it relates to the acquisition of two languages within the course of primary language development. Also found in this domain is work on foreign language acquisition. Often referred to as foreign language learning, it is distinguished by a lack of access to the L2 outside the classroom and by factors surrounding an individual learner's motivation and goals.

The largest body of work in the domain of language acquisition studies focuses on child L1 acquisition (FLA) and developmental psycholinguistics. The studies on FLA which have had a major impact on SLA research are those which were carried out as views advanced by Chomsky (1965) on language, the learner, and the learning process supplanted those framed by theories of structuralism and behaviorism. Their application to the study of SLA influenced its initial research questions and provided it with data collection instruments and analytical 
categories. This work focused on the extent to which SLA was like FLA in its processes and developmental sequences. A great deal of descriptive data was thereby made available to the field. These data provide basic details on the systematicity, sequences, and processes of SLA, which have inspired future research and informed teaching practice.

The study of SLA is believed to provide a particularly fruitful area for insight into the process of language learning compared to the study of children acquiring their L1. This is because the cognitive, conceptual, and affective processes that characterize L1 development are not required of their older, L2 learning counterparts (see Gass \& Ard 1985). On the other hand, the L2 learner's cultural background, personality and identity are unique resources that make the process of SLA an ever-present challenge to researchers. Fortunately, each of the fields has found a niche in the research endeavor, so there is little concern about whether the study of SLA or FLA is more central to questions on language acquisition. In the United States, this friendly co-existence seems especially confirmed by academic placement: Much of the academic study and research on FLA takes place in departments of psychology, whereas the study of SLA finds its place in departments of linguistics, applied linguistics, English as a Second Language, and education.

\section{TRADITIONS, TRENDS, CONCERNS AND CONTROVERSIES}

\section{Introduction}

Studies of SLA have existed for as long as parents have been keeping diaries of their children's language development (see Leopold 1939-1959, as an example, and Hatch 1978 for an overview). However, many SLA researchers would argue that the formal study of SLA was launched in 1967, with Corder's publication, "The significance of learners" errors" (Corder 1967). Its construct of "transitional competence," together with research on "interlanguage" (Selinker 1972) and data 
description through "error analysis" (Richards 1974), laid the groundwork for most of the early studies in the field, and has had an impact which is felt to date.

Since that time, moreover, the field of SLA has grown at a remarkable pace, so much so that in the course of a single paper, it is difficult to cover the enormous number of topics addressed, findings revealed, and factors considered in SLA research. Fortunately, many of these concerns and contributions are detailed in a wide range of textbooks (see, for example, R. Ellis 1994; Gass \& Selinker 1994; Larsen-Freeman \& Long 1991; Lightbown \& Spada 1999). Therefore, in the interest of observing a bi-directional perspective on the applications to and from SLA research and other fields, the paper will focus on those areas in which such a perspective is clearly apparent: the "linguistic" and the "learning" dimensions of SLA. The paper begins with a review of research on the linguistic sequences of interlanguage development.

\section{Research on Interlanguage Development}

Much of SLA research has focused on describing the learner's interlanguage and identifying sequences and patterns of development. The focus has been primarily on grammatical development. Since interlanguages are systematic, they follow rules and patterns that change over the course of L2 development, but do so in patterned ways.

When describing interlanguage development, researchers often cluster its patterns into interim grammars, which they refer to as developmental sequences or stages. Thus, learners are likely to omit grammatical morpheme endings in the early stages of learning, but overuse them at a later stage. For example, We play baseball yesterday We win might develop into We played baseball yesterday. We winned before past regular and irregular forms are sorted out. Learners are likely to utter I don't understand and she don't understand before they work through a

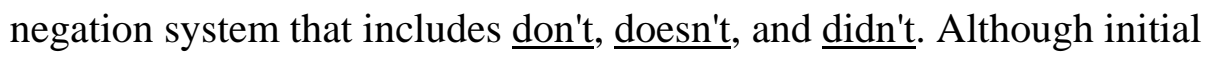
descriptions of interlanguage suggested that these errors were primarily, if not 
totally, developmental, there is now a great deal of support for the role of L1 transfer in error formation, as well as for the contributions made by universal strategies of communication and learning. Among the sentences above, for example, the learner's use of play in a context for played, are suggestive of processes of reduction or simplification, often used to manage emergent grammar or to communicate message content in the absence of morphosyntactic resources. Played and winned might reflect the learner's regularization of an emergent grammar, again for the purpose of its management or for communicating message meaning.

A great deal of the research on interlanguage development has focused on the learning of English, but there are also large bodies of work on French and German. Most interlanguage patterns are not language specific. Often they are referred to as 'errors,' but they are not isolated mistakes. Many reflect the learner's attempts at communication and learning, or at managing and processing L2 input. Others reflect grammatical complexities or input frequencies that transcend individual L2's.

The most widely studied and reported developmental sequences are the accuracy order identified in English grammatical morphology, the developmental sequences of English verb and phrase negation and the formation of questions and relative clauses. Much of this work has been carried out through methods and perspectives of FLA research. In addition, there is a large data base on developmental sequences for German L2. Its focus on the invariant sequence that German L2 learners follow in managing sentence constituent movement has lent considerable insight into the cognitive operations that underlie much of SLA. The sequences of L2 development, which will be described briefly in this section, provide a useful resource for teachers to apply to their attempts to understand their students' struggles, successes and progress with respect to SLA. (See discussions by Lightbown 1985, 2000; \& Pica 1994a) Attempts to explain the 
sequences from the perspectives of linguistic and cognitive theories will follow in a later section.

Morpheme Accuracy Order. Drawing on the work of Brown on morpheme orders in children learning English as their first language, Dulay and Burt $(1973,1974)$ asked to what extent L2 children reflected this sequence. Children from different L1 backgrounds, who were learning English in a variety of classrooms, were asked to describe pictures that provided contexts for their suppliance of grammatical morphemes such as plural $\underline{\text { s }}$ endings and verb functors. As learners described their pictures they revealed an 'accuracy order,' characterized by percentage of morpheme suppliance. In follow-up studies, this order, which came to be known as an 'average' or 'natural' order (Krashen 1977), held across spoken and written samples of children, adolescents, and adults, regardless of L1, whether or not formal instruction had been part of the learning experience. The 'average' order was thus a grouping of progressive -ing, noun plural $\underline{\text { s }}$ and copula, followed by a second grouping of article and progressive auxiliary, then past irregular, past regular, $3^{\text {rd }}$ person singular noun possessive $\underline{-s}$ The grouping of morphemes reflects the variability within the order. For example, accuracy for progressive -ing was found to be somewhat higher than that for noun plural $\underline{\text { s }}$ for some learners, whereas other learners were more accurate in their suppliance of copula compared to plural $\underline{\text { s. }}$. Still, on average, all three morphemes were supplied more accurately than article or progressive auxiliary.

The consistency of the morpheme accuracy order led to the view that SLA was a matter of 'creative construction,' and therefore much like FLA. SLA was seen as an implicit learning experience, based not on rule knowledge, but rather, on an innate capacity for L2 learning. Controversies ensued over whether such consistency in the order was a function of the statistics used to correlate the data. Explanations were advanced for the kinds of errors revealed in the morpheme data. For many learners, omission of L2 copula could be attributed to the absence 
of this morpheme in their L1, or its lack of salience and semantic transparency in the L2. As later research would reveal, the errors could be attributed to each of these factors, and for many learners, focused input and intervention were required for their correction. This work has helped to offset the view that SLA is exclusively a creative, implicit process.

Verb and Phrasal Negatives. Widely studied across many languages, negative structures appear to follow a similar sequence of development, which involves negative particle placement as well as verb tense and number marking. Initially, a negative particle, usually no or not, is placed next to the item it negates, as in no like or I no like. This juxtaposition reflects universal strategies of communication and grammar management. Thus all learners exhibit this stage. Those whose L1 negation is consistent with the stage, for example, L1 Spanish or Italian learners, usually remain there longer than those whose L1 does not encode negation in this way (See Zobl 1980, 1982). The next stage entails the use of an all purpose, more target like negator. In the case of English, this is usually don't. Later, the learner restructures don't for tense and number, so that didn't and doesn't appear.

Question formation. Learning to form questions involves multiple stages as well. As described in early case studies of children by Huang and Hatch (1978) and Ravem (1974), and in more recent work of Pienemann, Johnston and Brindley (1988), the stages involve the acquisition of yes/no and wh question types as well as inversion and fronting formation movements. Stage 1 is characterized by the use of single words and formulaic expressions, such as a store? what's that?, Many of these seem perfectly well formed, but they actually reflect learners attempts to communicate or to manage their still developing grammar. In stage 2, the learner uses declarative word order. In Stage 3, fronting of wh- words and do begin to appear, resulting in expressions such who you are? movie?, By Stage 4, inversion of wh in copular questions appears questions such as who are you? Inversion of copula and auxiliary is seen also in yes no questions 
as learners produce are you a student? and was she driving the car?. Stage 5 is characterized by the appearance of inversion in questions that require do-support to lexical verbs. Examples include do you like movies? and who is driving the car?. Stage 6 is characterized by the appearance of complex or less frequently used question forms Among the complex forms that emerge are question tags, as in she's French, isn't she,? and negative and embedded questions such as didn't you like the movie,? and do you know what the answer is,? respectively.

Relativization. The acquisition of relative clause structures relates to both the different sentence positions in which relativization can occur as well as the way in which it is encoded through the use of relative pronouns such as who, which, that), in substitution for their referent pronouns. These operations are seen as clauses such as the woman helps me with my English.and the woman is my

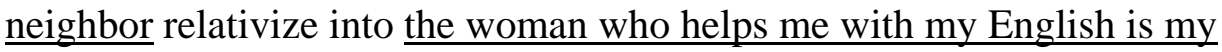
neighbor. Developmental sequences for relative clause formation follow a hierarchical order in which learners show greater accuracy for subject relativization. This was shown in the sentence just above. Next in the order is direct object relativization, represented in constructions such as the car that the man bought has a sunroof, composed from the man bought a new car.and the car has a sunroof. This is followed by indirect object and object of preposition relativization, evidence of which is seen respectively in the woman to whom I gave the money was grateful and the man from whom I borrowed the book has moved away. This sequence has been shown to reflect language typology and instructional sensitivity. Both topics will be discussed shortly.

Word Order. Finally, one of the most detailed and insightful studies of developmental sequences has been carried out on constituent movement and word order in German. Meisel, Clahsen, and Pienemann (1981) studied the untutored, non-instructed acquisition of German L2 by Gasterbeiter or guest workers, who had migrated to Germany from Eastern and Central Europe for short term employment. They were native speakers predominantly of Romance languages 
and Turkish. Drawing from both longitudinal case studies and cross-sectional group data, Meisel et al identified 5 stages:

Initially, the learners used individual words, phrases, unanalyzed formulas and chunks. In Stage 2, they moved on to simple sentence strings of sentence elements, usually subject-verb-object structures. In stage 3, they began to manipulate sentence constituents, seen mainly in adverbial movement from sentence final to sentence initial position. Thus she could read the book yesterday became yesterday she could read the book).

Next the learners separated sentence elements. In keeping with standard German word order, they moved non-finite lexical verbs from sentence internal to sentence final position. In this way, yesterday she could read the book could become yesterday she could the book read. The next stage was characterized by inversion, a more complex internal movement. Learners transformed structures such as yesterday she could the book read into yesterday could she the book read? This operation complied with German rules for verb initial placement in questions and adverbial phrases. In their final stage, the focus was on subordinate clauses, for which learners moved the finite verb to final position. Thus yesterday she could the book read would become although yesterday she the book could read. Notably absent from the sequences are grammatical morphemes, as these appeared to vary according to a learner's age, contact with native speakers of the L2, and opportunities for L2 use. This invariant sequence of stages, together with the variability of accuracy and appearance of other features, have been referred to as the Multidimensional Model.

R. Ellis (1989) studied instructed learners of German L2, and found the same sequence of development. Pienemann and Johnston $(1986,1987)$ applied the sequence to English, and cited the following stages. In stage 1, learners use single words and formulas. In stage 2, they use canonical word order. Stage 3 is characterized by fronting of 'do' for questions and appearance of negative particles in verb constructions. In stage 4, inversion appears in yes/no questions. In stage 5, 
$3^{\text {rd }}$ person singular and do-support appear, motivated by the need for noun-verb agreement. Pienemann and Johnston have claimed that this a sentence internal movement as it reflects the learner's management of both subject and verb structures. Complex structures such as question tags are seen in stage 6.

The Multidimensional Model has also been the focus of Pienemann's Teachability Hypothesis (Pienemann 1984). He was able to show that learners could accelerate their rate of $\mathrm{L} 2$ learning if presented with rules for constituent movement that corresponded with their next stage of development. If taught the rules of stages beyond their current level, the learners would not be able to internalize what they were taught. This finding has tremendous implications and applications to teaching decisions. Yet, as Cook (2001) has noted, even the most widely used, up to date textbooks, fail to follow the sequences that Pienemann has identified.

In more recent research, Multidimensional model has come to be known as the Processibility Model. This model is so named because it provides an explanation for stage progression and teachability predictions based on cognitive

processing constraints, These are related to the complexity of production required for each movement across the stages. In developing the Processibility Model, Pienemann has drawn from Slobin's work on "operating principles" (Slobin 1971, 1973, 1985), and from research on child FLA and bilingualism by Clahsen,(1984). Recently, Pienemann has linked these processing strategies with Lexicalist-Functional grammar in a study of Swedish L2 developmental sequences (Pienmenann and Haakenson 1997). Pienemann's newer perspective on SLA is much more cognitive in its undergirding than his Multidimensional Model. Other cognitively oriented research on SLA will be addressed later in this paper.

\section{Research on Second Language Acquisition Processes}


Introduction. This introductory section will review current theories in linguistics and psychology that have been applied to questions on the SLA process. Later sections will highlight their application to data on the sequences of interlanguage development, discuss some of the new questions and studies that the theories have motivated, and attempt to sort out the controversies that have been created by their presence in the field.

As an applied enterprise, SLA research has looked to linguistics and psychology to guide its questions, shape its hypotheses, and explain its findings. As often noted and lamented, SLA has not been grounded in its own comprehensive theory that can account for its sequences and processes, predict its outcomes, single out its most influential factors (see Long 1990 for a compelling discussion of this issue). As was discussed in the introduction to this paper, early research on SLA was guided by theories from structural linguistics and behaviorist psychology. As generative theories of language and psycholinguistic theories of learning came to the forefront of linguistics and psychology, their research methods made it possible for SLA researchers to collect a great deal of the interlanguage data described in the previous section.

More recently, newer theoretical perspectives on language and learning have been applied to the study of SLA. From linguistics, theories on universal properties and principles of language have shed light on the regularities and constraints that characterize interlanguage grammars, and have led to more principled research on the role of the L1 in the learning process. The nativist perspective on language acquisition that undergirds much of this research has served to invigorate the long-standing debate in the field as to the role of explicit rule learning in the SLA process and the need for explicit rule teaching in the classroom.

From psychology, cognitive theories have had a highly productive impact on SLA research and its applications. Cognitively-informed studies have revealed the ways in which learners process L2 input and use it to build and restructure 
their interlanguage grammar. New findings on cognitive processes of attention, awareness and practice have been used to explain the results of older studies. In addition, the interactions shown to promote these processes have revealed connections and applications to classroom practice.

Language Universals. The notion of a "universal" is not new to the field of linguistics, but has provided both explanations of SLA sequences and predictions of SLA outcomes. Language universals reflect consistencies in the typological or surface features of a broad range of world languages. These universal properties vary according to features such as their frequency and level of simplicity. Together, these comprise what linguists refer to as "markedness." For example voiceless alveolar stops such as (t) are considered "unmarked" as they are found among most languages.

Language universals also enter into implicational relationships. Thus, the presence of voiced alveolar stops such as /d/ in a language implies the presence of voiceless alveolar stops, e.g. /t./ The voicing on /d/ makes it more complex and marked than /t./ Since more languages have unmarked than marked features, the presence of a marked feature implies the presence of its unmarked counterpart.

The typological universal which has had the strongest role in explaining SLA sequences of development is the Noun Phrase Accessibility Hierarchy (NPAH), in which relative clauses formation follows an order that is consistent with principles of markedness. Thus, across languages of the world, subject noun phrases are more accessible to relativization than are direct object noun phrases, which are more accessible than indirect object, object of preposition, and comparative noun phrases. These are implicationally ordered, so that if a language allows relativization of indirect objects, it also allows relativization of direct objects.

English allows relativization of all noun phrases on the NPAH. Other languages such as Chinese, allow relativization of fewer phrases, but they still observe the ordering implications. This relationship across languages of the world 
also holds within interlanguages of learners, and can account for the order of acquisition of relative clause formation described in the previous section. As was shown, English L2 learners acquire the ability to form subject relatives before direct and indirect object relatives.

In addition to the explanatory role that the study of language universals has played in SLA research, it also has revealed predictive power. Several studies have shown that targeted instruction in relative clause formation at lower levels on the hierarchy, such as object of preposition, can generalize to acquisition at higher levels such as direct object (See Doughty 1991; Eckman, Bell, \& Nelson 1988; Gass 1980) This finding has not found its way into language curricula, despite its clear application to teaching practice.

The impact of the study of language universals on SLA research has also been seen in work on question formation. Research by Eckman, Moravcsik, \& Wirth (1989), for example, revealed an implicational relationship between question type and question process that was consistent both typologically and developmentally. Across languages, therefore, the presence of yes/no inversion implied the process of Wh inversion, and this latter implied Wh-fronting. Accordingly, this relationship could be seen developmentally as inverted yes/no questions such as are you a teacher? would emerge after inverted wh questions, as in who are you, themselves preceded as fronting was applied to questions such as who you are.? In this way the implicational order revealed in typological studies was reflected in the developmental data on question formation, at stages 3, 4 and 5.

The explanations and predictions offered through the perspective of language universals and the notion of markedness have given SLA researchers a fresh look at the role of transfer in SLA. As Eckman (1977) and Hyltenstam (1984) have shown, an L2 feature will be difficult if it is more marked linguistically in an absolute sense and even more so if it is more marked than its L1 counterpart. Thus, indirect object relativization or voiced stops would be more 
difficult to learn than subject relatives or voiceless stops, but would be even more difficult for those learners whose L1 was more limited in its scope of relativization or had only voiceless consonants. On the other hand, if the L2 feature were marked in the learner's L1, or even absent from it, its acquisition would not pose as much of a problem as long as the feature were unmarked in the L2. Thus, English learners of Chinese are able to suppress their L1 relative clause formation for objects of prepositions. English learners of German are able to suppress L1 voicing of final consonants in favor of unmarked, voiceless ones in German L2.

Principles of the construct of markedness, applied to interlanguage data development, can also explain why certain linguistic features are more difficult to notice than others, are less available in conversational input, and might qualify for focused instruction. These possibilities will be further explored in the discussion of cognitive processes.

Linguistic Universals. Linguistic Universals reflect constraints on the form of human languages. The linguistic universals that have had the most impact on SLA research are the innate principles of Universal Grammar (UG) that are viewed as a genetic endowment or property of mind, and a binary system of options, known as parameters, each with marked and unmarked settings that configure into a "core" grammar. The construct of markedness, which was central to work on universals of language typology, also plays a role in the study of linguistic universals.

Everyone who has fully acquired an L1, has constructed a core grammar, and has set the parameters of the core grammar in accordance with the L1. For example, individuals whose L1 is a "pro-drop" language must set this parameter into its simpler, unmarked setting. Thus, they might say I have three cats $\ldots$ are nice because they have set the pro-drop parameter so that pronoun referents are not needed in subject position. Those individuals whose L1 is a non-pro-drop language need to set their parameter in a marked setting, so that a subject pronoun 


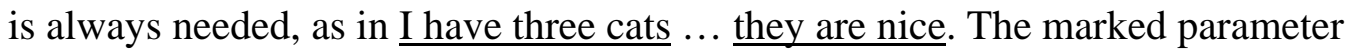
setting might be observed even in sentences where the subject pronoun held no meaning, as in it is snowing or there are 24 hours in a day. It is claimed that children begin learning their L1 as though the pro-drop and other parameters were in unmarked settings. Once confronted with marked input, they switch the parameters to marked settings.

There are three theoretical views on linguistic universals that have been addressed in studies of SLA. Many of these studies have focused on the principle of "subjacency," which has to do with wh- movement within sentences. Some languages allow more movement than others, and some do not observe the principle at all. Thus, studies of L2 learners whose L1 follows subjacency rules that are different from the L2 provide a good basis for determining the role of UG in SLA.

The strongest view is that SLA is like FLA, and learners have access to the principles and unmarked parameters of UG in much the same way that they did during FLA. They therefore begin interlanguage development through unmarked parameter settings, not through their parameterized core grammar. There is evidence in support of this view in research by Bley-Vroman, Felix, and Ioup (1988), who found that Korean L1 learners of English were able to recognize English sentences which followed the principle of subjacency for wh movement, even though this principle is not observed in Korean. This finding illustrated that L2 learners are sensitive to universal principles, even when those principles have not been realized in their L1.

Another view is that L2 learners fall back on the parameterized core grammar of their L1, but are able to reset it for the L2, even when confronted with marked data that conflicts with their L1. Support for this position comes from White (1985). She found that Spanish L1 learners of English L2 relied initially on their L1 setting for pro-drop when making grammaticality judgments of English sentences, whereas French L1 learners of English did not appear to do so. In 
Spanish, the pro-drop parameter has an unmarked setting, but in English and French, the setting is marked. Over time, however, the Spanish learners' grammaticality judgments were as accurate as those of the French learners. This result suggested that they were able to reset their L1 parameter for the marked English L2 setting.

Yet another view is that L2 learners are not able to draw on UG principles to reset the parameters of their core grammar, but instead rely on cognitive principles of learning and apply them to their L2 development. SLA is thus experienced as a conscious, problem solving activity. Such a view accounts for the errors produced by L2 learners as they attempt to manage and control interlanguage grammar.

One of the most compelling reasons for application of linguistic universals to questions about SLA is that the principles and parameters represent constituents and operations that transcend individual languages. This offers excellent opportunities to further explore the role of transfer in L2 learning, to see how it affects aspects of grammar that are considered to be outside the UG core. Findings from such research can shed further light on current assumptions as to which principles and parameters are actually universal and which are subject to L1 constraints. Even more important is the fact that perspectives on linguistic universals provide SLA with both a theory of language and a theory of language learning.

However compelling they appear, however, theoretical views on linguistic universals pose several difficulties with respect to their application to SLA research. One difficulty is methodological. Most of the research involved with linguistic universals has asked learners to judge the grammaticality of sentences that reflect the linguistic principle or parameter under study. Uusually they are asked to read or listen to sentences and give a yes or no judgment. Such an approach is in keeping with assumptions used throughout theoretical linguistics on the validity of native speaker intuition as a reflection of language competence. 
However, results of studies which use grammaticality judgment data are difficult to compare with those based on descriptive, interlanguage samples.

A second difficulty with linguistic universals lies in their perceived relevance to the study of SLA. Most consumers of SLA research are used to discussing it with reference to transcribed samples of interlanguage speech or frequency tables of interlanguage features. When they read about research findings on interlanguage, they expect reference to functional and inflectional features such as articles or tense markers. Yet, these are the very features considered peripheral to the core grammar. Further, when core grammar parameters are addressed, this is done through terms such as "subjacency" rather than through familiar terminology on wh-questions. This further limits comparison with data from other research.

A further difficulty with the application of perspectives on linguistic universals to SLA research relates to explanation of findings. Learner forms attributed to unmarked parameter settings can often be explained with reference to universal processes of simplification that have long held a place in interlanguage analysis. Thus, the question remains as to whether the learners who say is raining are doing so because they are observing the unmarked setting of the pro-drop parameter, have chosen to omit the semantically empty it as an agent in their message, or have not yet perceived it in the L2 input around them.

Many questions remain regarding linguistic universals as a driving force behind SLA questions, and as an explanation of SLA data. Some of these pertain to competing findings within this perspective on SLA; others are related to terminological inconsistencies with studies across the field. Over time, and with persistence, these matters can open up opportunities for further study and new lines of research, which will lead to greater understanding of the SLA process.

Cognitive Theories. Cognitive theories are concerned with mental processes used for skill building and skill learning. Thus, when SLA research is carried out within a cognitive perspective, the L2 is viewed as a skill, and its 
acquisition as a linguistic system is assumed to be built up gradually through processes of attention, conscious awareness and practice.

To some researchers, a view of SLA that includes cognitive processes such as attention, awareness and practice is inconsistent with theoretical assumptions of interlanguage research, and with universal perspectives on language acquisition. This is because most researchers have viewed SLA as an implicit experience, guided by the learner's interaction with L2 input. To them, the cognitive process of attention is important, but mainly because it promotes understanding of meaning not because it facilitates skill learning. They associate cognitive constructs such as conscious awareness and practice with behaviorist theories of learning, dismissed from the field several decades ago.

Yet most SLA researchers who apply cognitive theories to inform their questions and methods, do so under the assumption that SLA is indeed a largely implicit process. For them, cognitive theories are not alternate views on SLA. Instead, they are applied to research in order to better understand, and to possibly explain, why it is that, for many learners, an implicit experience of transacting L2 message meaning is not sufficient for achieving L2 grammatical competence.

Many L2 learners, for example, struggle with linguistic features that are difficult to notice in the messages they hear. These are often outside the scope of UG principles and parameters, and therefore can be affected by any number of internal and external factors, or never acquired at all. Other learners report that they can understand the meaning of a message without the need to focus on the many forms that encode it. Even young learners have been shown to have strong L2 comprehension, but lack grammatical proficiency. Some learners have internalized versions of the L2 that are functionally adequate for communicative purposes, but developmentally incomplete in form and structure. The consequences of this are non-standard, stable, immutable, "fossilized" interlanguage varieties. These varieties were introduced to the field by Selinker in 
1974, and have continued to challenge researchers, teachers, and of course, fossilized L2 learners, to date.

Many of these concerns about SLA have been expressed as research questions about the quality and accessibility of L2 input that can best serve learners as data for their learning. Therefore the remaining discussion of cognitive processes will focus primarily on research about their role in assisting learners to notice L2 input and apply it to their learning.

Cognitive Processes, Input and Interaction. That samples of L2 are needed by learners as a source of input for their learning has long been a basic assumption of SLA research. Corder (1967) distinguished between the input that is available to L2 learners and that which individual learners can actually use as intake for building interlanguage grammar, given their stage of development. Decades ago, Krashen argued that 'comprehensible input' was necessary and sufficient for successful SLA (see, for example, Krashen 1977). He described such input as understandable in its meaning, but slightly beyond the learner's current level of development with respect to its linguistic form. Both "intake" and "comprehensible input" were conceptually intriguing, but they did not lend themselves to testable hypotheses about SLA processes.

Long $(1980,1981,1985)$ also argued that comprehensible input was crucial to SLA, but his research revealed that it was the learners' interaction with interlocutors that mattered as much as the input directed to them. Thus, when input was no longer comprehensible during interaction between L2 learners and interlocutors, they would modify the flow of the interaction and repeat, rephrase, or request help with the input until comprehension was achieved. It was claimed that the modified input directed toward the learners could assist their comprehension as well as their L2 learning.

Follow-up studies of such interaction, which Long referred to as the "negotiation of meaning," were carried out by Long and others (for example, Gass \& Varonis 1994; Mackey 1999; Pica, Holliday, Lewis \& Morgenthaler 1989; 
Pica, Holliday, Lewis, Berducci \& Newman 1991). Their analyses revealed that, as learners and interlocutors attempted to achieve comprehensibility, they repeated and rephrased initial messages, and extracted and highlighted words and phrases in patterned ways that often had developmental consequences. Pica et al $(1989,1991)$ showed that the extent to which learners worked at these manipulations was directly related to the open endedness of the questions they were asked. Gass and Varonis (1994) showed that interlanguage items negotiated in an initial conversation would be accurately encoded in the learner's later production. Mackey (1999) revealed that learners' active participation in negotiation was closely connected to their development of L2 English question forms.

An analysis by Pica (1994b) showed that these extractions often revealed L2 grammatical relationships as they encoded message meaning. For example, in response to the learner's initial utterance which encoded a noun phrase in subject position, a listener might extract the noun phrase, topicalize and repeat it in object position. Thus, the listener might ask about the students watch the movie by recoding it as the students? what did you say about the students?. Such modifications appeared to give learners repeated access to L2 form as it encoded message meaning. This was the very kind of L2 input that could be used as intake for grammar building, restructuring, and internalization.

Since SLA was considered to be a subconscious, implicit process in terms of the learner's mental involvement, there did not seem to be a push to explore the cognitive side of the input-intake-internalization progression. SLA models based on information processing theory and cognitive processes (see, for example McLaughlin 1978) were rejected by Krashen for their emphasis on the role of consciousness, which Krashen considered unnecessary for SLA, and possibly detrimental to the learner's progress.

Cognitive Processes and Evidence. Increasingly, researchers have come to observe that $\mathrm{L} 2$ learning is a much more conscious experience than was 
heretofore believed. Drawing on his own experience as a Portuguese L2 learner in and out of classrooms in Brazil, Schmidt found that cognitive processes such as attention and noticing were crucial to his L2 learning. The frequency with which he heard complex features of Portuguese, and the salience of their form or position in input were two factors that helped Schmidt to notice them. Schmidt also found that in order to incorporate many features of Portuguese into his developing L2 grammar, he needed to "notice the gap" between such features as they were used by other speakers, and how own interlanguage encodings. Here, too, his noticing was aided by the frequency and saliency of a feature, the communicative and cognitive demands of the situation in which he found himself, and his readiness to "notice the gap."

Schmidt's observations, along with findings on communicative, contentbased classroom contexts, considered rich in L2 input (Pica 2002; Swain 1985), have revealed that comprehensible input, however modified, might not be efficient, or even sufficient, for SLA. Thus, new questions have emerged about the kinds of input learners need to achieve a successful L2 outcome. Long addressed these questions in several publications, including Long (1996) and Long, Inagaki, \& Ortega (1998). Drawing from not only Schmidt's arguments and findings, but also from FLA theory and research, and from studies of L2 formfocused instruction (such as those of Spada \& Lightbown, 1993; White, 1991; White, Spada, Lightbown \& Ranta, 1991) and experimental intervention (Oliver, 1995), Long distinguished between input that provides positive evidence of relationships of L2 form, function and meaning, and input that supplies negative evidence on forms and structures that are used by learners, but are not consistent with the L2 they are learning.

According to Long, sources of positive evidence include spoken and written texts that are in their authentic state, as well as those that have been modified for comprehensibility in ways described above. Learners can access negative evidence through explicit corrective feedback, or implicit feedback. 
Included among this latter are requests such as could you say that again? and expressions such as huh? which ask learners to clarify or repeat utterances that can't be understood. Also included are "recasts," which essentially repeat what a learner has just said in a more accurate way. For example I need pencil might be recoded as You need a pencil. The most effective recasts appear to be those which focus on only one grammatical feature over the course of a conversation or lesson (Doughty \& Varela 1998). When teachers recast of a range of student misproductions, the students fail to distinguish them from other follow up moves that teachers use to conduct their lessons. (Lyster 1998).

Among the cognitively-oriented interventions that appear to heighten the learner's access to L2 input for both positive and negative evidence are instruction on how best to process input for form and meaning (Van Patten \& Oikkenon 1996; Van Patten \& Sanz 1995), the learner's interaction with meaningful materials, enhanced both graphically and linguistically to highlight form and meaning relationships (Doughty 1991), problem solving, information exchange and other goal oriented, task based activities.(Pica, Billmyer, Julian, Blake-Ward, Buccheit, Nicolary, \& Sullivan 2001; Pica, Kanagy, \& Falodun 1993), and activities that foster learners' communication about grammar.(Fotos 1994; Fotos \& Ellis 1991; Loschsky \& Bley-Vroman 1993; Pica, Billmyer, Julian, BlakeWard, Buccheit, Nicolary, \& Sullivan 2001).

In addition to the positive and negative evidence that comes from modified input, feedback, and formal instruction, Swain has argued that learners' own production can provide a basis for learning of $\mathrm{L} 2$ relationships of form and meaning (Swain 1985, 1995, 1996). Based on extensive observational data of learner exchanges, she has identified several ways in which this can occur. First, she found that when asked to modify their message production toward greater comprehensibility or precision, learners moved from their rudimentary interlanguage grammar, in which relationships among sentence elements were often characterized by simple juxtaposition of relevant words, to more advanced, 
syntactic processing and message organization. Thus learners might modify Philadelphia live to I live in Philadelphia, when asked to clarify their message meaning.

In addition, learners' conversations would often engage them in discussion of the linguistic dimensions of their interaction, a process Swain refers to as "metatalk." Finally, Swain claims that learners' production can also help them to "notice the gap" between their output and input. Swain has placed her work within a collaborative, sociocultural perspective, while other output-focused researchers have found results consistent with hers, and have been able to explain them in terms of cognitive processes.(see for example, deBot 1996). Thus there is strong support for the role of production in SLA, across social and cognitive perspectives.

Cognitive Perspectives on L2 Knowledge. Theoretical claims that L2 learning is a much more conscious process than was heretofore believed, and an experience that can benefit from both input and feedback, have reactivated the long standing debate in the field regarding L2 learning and its relation to L2 knowledge. This debate, once known almost exclusively, as Krashen's "acquisition" vs. "learning" distinction (see again, Krashen 1977, 1981 as well as Krashen's recent writings, for example, Krashen 1994), centers on three positions regarding the interface of implicit and explicit L2 learning and resultant L2 knowledge.

The first position is a non-interface position, i.e., that SLA is an altogether implicit activity. While explicit L2 learning and explicit L2 knowledge are possible, they remain separate from the L2 competence that learners come to acquire. This position is consistent with nativist perspectives drawn from theories on linguistic universals (for example Schwartz 1986) and with Krashen's Monitor Theory (Krashen 1977, 1981), which have been used to account for the regularities of L2 development. However it does not account for the incomplete acquisition experienced by fossilized learners. 
A very different position is the strong interface position, supported through studies by DeKeyser (1997), N. Ellis (1993, 1994), and Robinson (1997). This position, motivated by information processing theory (see McLaughlin 1978, 1996; O'Malley, Chamot, \& Walker 1988), holds that explicit L2 knowledge, attained through explicit learning, can become implicit L2 knowledge. This is generally achieved through practice in which learners deliberately focus their attention on L2 form as it encodes message meaning and work toward understanding and internalization. Many studies have shown support for this view. Carefully controlled in design, they tend to focus on very specific features and highly experimental conditions. Additional support has come from the metaanalysis and comparison or experimental and quasi-experimental studies on the effect of L2 instruction (Norris \& Ortega 2001) on L2 learning. Together, individual studies and the meta-analysis of different kinds of studies indicate that the strong interface position is indeed a valid one, but might apply to contextspecific dimensions of SLA.

Finally, there is a position known as the "weak" interface position, although it is much more robust than the other two positions in its number of supporters and supportive studies. Here, SLA is viewed as a predominantly implicit activity. However, it is believed that L2 knowledge can be built up through both explicit instruction and other interventions that enable learners to notice crucial relationships of L2 form and meaning that are difficult, if not impossible, for them to learn without such intervention. This is a view held by not only those who carry out research strictly within the cognitive perspective, but also among researchers associated with strategies of consciousness raising (Rutherford \& Sharwood Smith 1985) and those who work within a perspective that has come to be known as "focus on form." This work was initiated by Long (1991), and has been sustained by studies gathered in a volume edited by Doughty and Williams (1998) (see, for example, papers by Harley; Lightbown; Long \& 
Robinson; Swain; and Doughty (Doughty \& Varela) and Williams (Williams \& Evans), themselves.

The evidence in support of this "weak" position illustrates ways in which all three positions are correct, as each is conditioned by factors that are learnerrelated, stage-specific, language-related. Many of these factors need further exploration. Others have yet to be identified. Together with other needs across the field of they augur well for a solid future for SLA research. The paper will therefore close with a brief look toward that future.

\section{CONCLUSIONS AND FUTURE DIRECTIONS}

This paper has aimed to highlight the ways in which SLA research, across the past three decades, has retained its original applied and linguistic interests, and enhanced them through greater attention to questions on acquisition processes. New research, carried out from the perspectives of linguistic and language universals and cognitive activities, has shed much light on the complexities of L2 development and the input and interactional needs of L2 learners. Application of findings from this research has rekindled old debates on the role of consciousness in L2 learning, and uncovered new and necessary ways to study corrective feedback and L2 practice, beyond a behaviorist point of view.

Many questions remain unanswered. Others are in need of more complete answers. The three positions on the role of UG remain unresolved. Is each correct, according to linguistic feature studied? Is one more relevant to UG, the others, more reflective of peripheral grammars? Continued research along these lines can contribute to a theory of L2 learning and inform theoretical linguistics as well. The study of the learner's L1 in relation to markedness and language universals has shown much promise. The classroom relevance of this research is already apparent, and that in itself should motivate additional studies.

Researchers need to continue to identify form-meaning relationships that defy the learner's grasp, and yet are outside of UG, and therefore not learnable from unmodified input or positive evidence alone. The construct of markedness 
can play a role in their identification. Those forms whose encodings of meaning are not salient, are infrequent or highly complex, or are embedded in specialized registers such as academic or professional discourse, are likely to require focused practice and repeated positive evidence, or various kinds of negative evidence to stimulate their learning. Future studies will need not only to identify the forms whose meaningful encodings are difficult to acquire, but also to design activities that help learners to notice them through focused input and negative evidence.

Researchers must also develop ways to operationalize and study processes of restructuring and internalization that occur after learners have noticed input and processed it as intake. The interventions designed to stimulate these processes will not only provide data on the input - intake - restructuring- internalization progression, but will serve as a basis for materials and activities that can be applied to classroom needs.

As new findings emerge on the role of consciousness and attention in the learning process, their relevance to the classroom is evident. However, there is an urgent need to operationally define these processes, lest they be mis-applied to classroom practice in behaviorist rather than cognitive terms.

A consistent theme throughout SLA research has been the need for longitudinal data. The handful of longitudinal studies that have been carried out have made an impressive impact on the field, the most recent that of Schmidt and Frota (1986). The kind of longitudinal research needed at present must take the form of follow-up studies that check retention of features learned through instructional intervention and practice. Although it is clear that feedback and focused input can make a difference in the short term, their trusted application to classroom practice will require confidence in their long term impact.

The relevance of classroom practice in informing SLA research and in being informed by its results will find SLA researchers and SLA practitioners working together to design studies and interpret their findings. This has already become apparent among classroom studies. Lingering linguistic questions, as 
described above, suggest a need for teamwork with linguists as well. Opportunities for such research teams to collaborate, sharing and exchanging roles and responsibilities, as well as to work together in complementary roles, will bring greater efficiency as well as theoretical and pedagogical relevance to SLA research.

The field has increased in size and scope, yet it is still sufficiently focused on questions of learning and teaching for many voices and perspectives to be acknowledged. The fact that corrective feedback and focused practice are now viewed as cognitive processes, and are at the forefront of research interest, suggests that the field is still open for a fresh look at processes once discarded or nearly forgotten, as long as the evidence to support them is abundant and convincing. That is how learner errors came to be seen as a learning processes rather than bad habits, and how communication and comprehension came to be acknowledged as insufficient for L2 competence. Lingering questions and concerns at present will continue to lead the way to future studies. New and currently unforseen directions will be taken. The richness and complexity of SLA as an learning process and a field of study suggest that there are many perspectives to apply and many more applications to be found.

\section{REFERENCES}

Bley-Vroman, R., Felix, S., \& Ioup, G. (1988).The accessibility of Universal grammar in adult language learning. Second Language Research, 4, 1-32.

Chomsky, N. (1965). Aspects of the theory of syntax. Cambridge, MA: MIT Press.

Clahsen, H. (1984). The comparative study of first and second language development. Studies in Second Language Acquisition, 12, 135-154.

Cook, V. (2001). Second language learning and language teaching. London: Arnold Publishers.

Corder, S.P. (1967). The significance of learners' errors. International Review of Applied Linguistics, $\underline{5}, 161-169$. 
de Bot, K. (1996). Review article: The psycholinguistics of the output hypothesis. Language Learning, 46, 529-555.

deGraff, R. (1997). The eXperanto experiment: Effects of explicit instruction on second language acquisition. Studies in Second Language Acquisition, 19, 249-276

DeKeyser, R. (1997). Beyond explicit rule learning: Automatizing second language morphosyntax. Studies in Second Language Acquisition, 19, 1-39.

DeKeyser, R. (1998). Beyond focus on form: Cognitive perspectives on learning and practicing second language grammar. In C. Doughty, \& J. Williams (Eds.), Focus on form in classroom second language acquisition (pp. 42-63). Cambridge: Cambridge University Press.

Doughty, C. (1991). Instruction does make a difference: The effect of instruction on the acquisition of relativization in English as a second language. Studies in Second Language Acquisition, 13, 431-469.

Doughty, C. (2002). Cognitive underpinnings of focus on form. In P. Robinson (Ed.), Cognition and Second Language Learning (pp. 206 - 257). Cambridge: Cambridge University Press.

Doughty, C., \& Varela, E. (1998) Communicative focus on form. In C. Doughty, \& J. Williams (Eds.), Focus on form in second language classroom (pp. 114138). New York: Cambridge University Press.

Doughty, C,. \& Williams, J. (Eds.), (1998). Focus on form in second language classroom. New York: Cambridge University Press.

Dulay, H., \& Burt, M. (1973). Should we teach children syntax? Language Learning, 23, 245-258.

Dulay, H., \& Burt, M. (1974). Natural sequences in second language acquisition. Language Learning, 24, 37-58.

Eckman, F. (1977). Markedness and the contrastive analysis hypothesis. Language Learning, 27, 315-330.

Eckman, F., Bell, L. \& Nelson, D. (1988). On the generalizability of relative clause instruction in the acquisition of English as a second language. Applied Linguistics, $\underline{9}, 1$ 20. 
Eckman, F., Moravcsik, E.A., \& Wirth, J.R.. (1989). Implicational universals and interrogative structures in the interlanguage of ESL learners. Language Learning, $\underline{39}$, 138-155.

Ellis, N. (1993). Rules and instances in foreign language learning: Interactions of implicit and explicit knowledge. European Journal of Cognitive Psychology, $\underline{5}$, 289-319.

Ellis, N. (1994). Vocabulary acquisition: The implicit ins and outs of explicit cognitive mediation. In N. Ellis (Ed.). Implicit and explicit learning of languages (pp. 211-282). London: Academic Press.

Ellis, R. (1989). Are classroom and naturalistic acquisition the same?: A study of the classroom acquisition of German word order rules. Studies in Second Language Acquisition, 11, 305-328.

Ellis, R. (1994). The study of second language acquisition. London: Oxford University Press.

Felix, S. (1985). More evidence on competing cognitive systems. Second Language $\underline{\text { Research }} \underline{1}$, 47-72.

Fotos, S. (1994). Integrating grammar instruction and communicative language use through grammar consciousness-raising tasks. TESOL Quarterly, 28, 323-351.

Fotos, S., \& Ellis, R. (1991). Communicating about grammar: A task-based approach. TESOL Quarterly, 25, 605-628.

Gass, S. (1982). From theory to practice. In M. Hines, \& W. Rutherford (Eds). $\underline{\text { On }}$ TESOL '81 (pp. 120-139). Washington, D.C.: TESOL.

Gass, S., \& Ard, J. (1984). Second language theory and the ontology of language universals. In W. Rutherford (Ed.), Language universals and second language acquisition (pp. 33-68). Amsterdam: John Benjamins.

Gass, S., \& Selinker, L. (1994). Second language acquisition: An introductory course. Mahwah, NJ.: Lawrence Erlbaum Associates.

Gass, S., \& Varonis, E. (1994). Input, interaction and second language production. Studies in Second Language Acquisition, 16, 283-301. 
Harley, B. (1998). The role of focus-on-form tasks in promoting child L2 acquisition. In C. Doughty, \& J. Williams (Eds.), Focus on form in classroom second language acquisition (pp. 156-174). New York: Cambridge University Press.

Hatch, E. (Ed.). (1978) Second language acquisition: A book of readings. Rowley, MA: Newbury House.

Huang, J., \& Hatch, E., (1978). A Chinese child's acquisition of English. In E. Hatch (Ed.), Second language acquisition: A book of readings (pp. 118-131). Rowley, MA: Newbury House.

Hyltenstam, K. (1987). Markedness, language universals, language typology and second language acquisition. In C, Pfaff (ed.), First and second language acquisition processes (pp. 55-78). Cambridge, MA: Newbury House.

Krashen, S. (1977). Some issues relating to the monitor model. In H.D. Brown, C. Yorio, \& R. Crymes (Eds.), On TESOL '77: Teaching and learning English as a second language: Trends in research and practice (pp. 144-158). Washington, D.C.: TESOL.

Krashen, S. (1981). Second language acquisition and second language learning. Oxford: Pergamon.

Krashen, S. (1994). The Input Hypothesis and its rivals. In N. Ellis (Ed.), Implicit and explicit learning of languages (pp. 45-77). London: Academic Press.

Lado, R. (1957). Linguistics across cultures: Applied linguistics for language teachers. Ann Arbor: The University of Michigan Press.

Larsen-Freeman, D.,\& Long, M. (1991). Second Language Research. New York: Longman.

Leopold, W.F. (1939 - 1949). Speech development of a bilingual child: a linguist's record, 1939, 1947, 1949, (Vol. 1) Vocabulary growth in the first two years. (Vol. 2) Sound learning in the first two years. (Vol. 3) Grammar and general problems in the first two years. (Vol. 4) Diary from age 2. Evanston, IL: Northwestern University Press. 
Lightbown, P. Great expectations: Second-language and classroom teaching. Applied Linguistics, 6, 173-189.

Lightbown, P. (1998). The importance of timing in focus on form. In C. Doughty, \& J. Williams (Eds.), Focus on form in classroom second language acquisition (pp. 177-196). New York: Cambridge University Press.

Lightbown, P. (2000). Anniversary Article: Classroom SLA research and second language teaching. Applied Linguistics, 21, 431-462.

Lightbown, P., \& Spada, N. (1990). Focus on form and corrective feedback in communicative language teaching: Effects on second language learning. Studies in Second Language Acquisition, 12, 429-448.

Lightbown, P,. \& Spada, N. (1999). How languages are learned. (2nd ed.). London: Oxford University Press.

Long, M. (1981). Input, interaction, and second language acquisition. In H. Winitz (Ed.), Native and foreign language acquisition (pp. 259-278): Annals of the New York Academy of Sciences, (Vol.) 379.

Long, M. (1985). Input and second language acquisition theory. In S. Gass , \& C. Madden (Eds.), Input in Second Language Acquisition (pp. 377 - 393). Rowley, MA: Newbury House.

Long, M. (1990). The least a second language acquisition theory needs to explain. TESOL Quarterly, 24, 649-666.

Long, M. (1991). Focus on form: A design feature in language teaching methodology. In K. deBot, R. Ginsberg, \& C.Kramsch (Eds), Foreign language research in cross-cultural perspective (pp. 39-52). Amsterdam: John Benjamins.

Long, M. (1996). The role of the linguistic environment in second language acquisition. In W. C. Ritchie, \& T. K. Bhatia (Eds.), Handbook of language acquisition (Vol. 2): Second language acquisition (pp. 413-468). New York: Academic Press. 
Long, M., Inagaki, S., \& Ortega, L. (1998). The role of implicit negative evidence in SLA: Models and recasts in Japanese and Spanish. The Modern Language Journal, 2, 357-371.

Long, M., \& Robinson, P. (1998). Focus on form: Theory, research, and practice. In C. Doughty, \& J. Williams (Eds.), Focus on form in classroom second language acquisition (pp. 15-41). New York: Cambridge University Press.

Loschky, L. \& Bley-Vroman, R. (1993). Creating structure-based communication tasks for second language development. In G. Crookes, \& S. Gass (Eds.)Tasks and language learning. (Vol. 1) (pp. 123-167). Clevedon: Multilingual Matters

Lyster, R. (1998). Recasts, repetition, and ambiguity in L2 classroom discourse. Studies in Second Language Acquisition, 20, 51-81.

Mackey, A. (1999). Input, interaction, and second language development. Studies in Second Language Acquisition, 21, 557-588.

McLaughlin, B. (1996). Information processing in second language acquisition. In W. C.

Ritchie,\& T. K. Bhatia (Eds.), Handbook of language acquisition. Vol. 2, Second language acquisition. New York: Academic Press.

McLaughlin, B. (1978). The monitor model: Some methodological considerations. Language Learning, 28, 309-332.

Meisel, J., Clahsen, H. \& Pienemann. M. (1981). On determining developmental stages in natural second language acquisition. Studies in Second Language Acquisition, $3,109-$ 35.

Norris, J., \& Ortega, L. (2001). Does type of instruction make a difference? Substantive

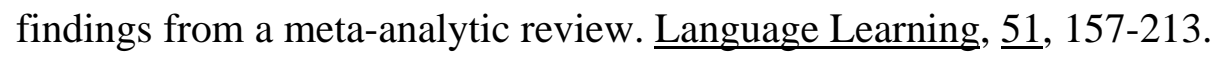

Oliver, R. (1995). Negative feedback in child NS/NNS conversation. Studies in Second Language Acquisition, 17, 559-482.

O'Malley, J., Chamot, A., \& Walker, C. (1987). Some applications of cognitive theory to second language acquisition. Studies in Second Language Acquisition, 9, 287-306. 
Pica, T. (2002). Subject matter content: How does it assist the interactional and linguistic needs of classroom language learners? The Modern Language Journal, 85, 1-19.

Pica, T. (1994a). Questions from the classroom: Research perspectives. TESOL Quarterly, 28, 49-79.

Pica, T. (1994b). Research on negotiation: What does it reveal about second language learning conditions, processes, and outcomes? Language Learning, 44 , 493-527.

Pica, T., Billmyer, K., Julian, M. A. Blake-Ward, M., Buchheit, L., Nicolary, S. \& Sullivan, J. (2001). From content-based texts to form focused tasks: an integration of second language theory, research, and pedagogy. Presentation to annual AAAL Conference, February 2001, St. Louis, MO.

Pica, T., Holliday, L., Lewis, N.,\& Morgenthaler, L. (1989). Comprehensible output as an outcome of linguistic demands on the learner. Studies in Second Language Acquisition, 11, 63-90.

Pica, T., Kanagy, R., \& Falodun, J. (1993). Choosing and using communication tasks for second language instruction. In G. Crookes, \& S. Gass (Eds.) Tasks and language learning. Vol. 1 (pp. 9-34). Clevedon: Multilingual Matters.

Pienemann, M. (1989). Is language teachable? Psycholinguistic experiments and hypotheses. Applied Linguistics, 10, 52-79.

Pienemann, M., \& Haakenson,, H. (1999). A unified approach towards the development of Swedish as L2: A Processibility account. Studies in Second Language Acquisition, 21, 383-420.

Pienemann, M., \& Johnston, M. (1986). An acquisition-based procedure for language assessment. Australian Review of Applied Linguistics, 9, 92-112.

Pienemann, M., Johnston, M., \& Brindley, G., (1988) Constructing an acquisition-based procedure for second language assessment. Studies in Second Language Acquisition, 10, 217-243.

Ravem, R. (1968). Language acquisition in a second language environment. International Review of Applied Linguistics, 6, 165-185. 
Richards, J.C. (1974). Error analysis. London: Longman.

Robinson, P. (1997). Automaticity and generalizability of second language under implicit, incidental, enhanced, and instructed conditions. Studies in Second Language Acquisition, 19, 233-247.

Rutherford, W., \& Sharwood Smith. M. (1985). Consciousness-raising and universal grammar. Applied Linguistics, $\underline{6}$, 274-282.

Schmidt, R. (1990). The role of consciousness in language learning. Applied Linguistics, 11, 17-46.

Schmidt, R. (1992). Psychological mechanisms underlying second language fluency. Studies in Second Language Acquisition, 14, 357-385.

Schmidt, R., \& Frota, S. (1986). Developing basic conversational ability in a second language: A case study of an adult learner of Portuguese. In R. Day (Ed.), Talking to learn: Conversation in second language acquisition (pp. 237-326). Rowley, MA: Newbury House.

Schwartz, B. (1993). On explicit and negative data effecting and affecting competence and linguistics behavior. Studies in Second Language Acquisition, $\underline{15}, 147-163$.

Selinker, L. (1972). Interlanguage. International Review of Applied Linguistics, $\underline{10}, 209-231$.

Slobin, D. I. (1973). Cognitive prerequisites for the development of grammar. In C.A. Ferguson, \& D.I. Slobin (Eds.), Studies of child language development. New 